\title{
Modelagem numérica de ressacas na plataforma sudeste do Brasil a partir de cartas sinóticas de pressão atmosférica na superfície
}

\author{
Ricardo de CAMARGO ${ }^{1}$ \& Joseph HARARI ${ }^{2}$ \\ ${ }^{1}$ Centro de Estudos do Mar da Universidade Federal do Paraná \\ (Av. Beira Mar s/n, 83255-000, Pontal do Sul, PR, Brasil) \\ ${ }^{2}$ Instituto Oceanográfico da Universidade de Sāo Paulo \\ (Caixa Postal 66149, 05389-970, São Paulo, SP, Brasil)
}

\begin{abstract}
- Abstract: A three-dimensional, linear, barotropic and meso-scale numerical model is used for the southeastern Brazilian shelf, in order to represent the composition of the main astronomical tidal constituents, superimposed to extreme meteorological effects, for specific periods of interest. However, meteorological data relative to this area are very few and sparse, so that a methodology to provide meteorological conditions to the oceanic circulation model was used, based only on atmospheric pressure charts at the surface. The pressure field was well represented, while the calculated wind speeds were much larger than the observed winds at the coast. The model results indicate that it is possible to associate the predominant high pressure center in the South Atlantic and the correspondent surface elevations parallel to the coastline to an approximately geostrophic oceanic circulation system. On the other hand, the passage of cold fronts in the area induces transient systems that modify the geostrophic pattern, also changing the surface elevation isolines configuration.
\end{abstract}

- Resumo: Um modelo numérico tri-dimensional, linear, barotrópico e de meso-escala, é usado para a plataforma sudeste brasileira, de maneira a representar a composiçāo das principais componentes astronômicas de maré, sobrepostas a efeitos meteorológicos extremos, para períodos específicos de interesse. No entanto, como dados meteorológicos relativos a esta área são muito escassos e esparsos, foi utilizada uma metodologia de fornecimento de condições meteorológicas para o modelo de circulação oceânica, baseada somente em cartas sinóticas de pressão atmosférica na superfície. O campo de pressāo foi bem representado, mas as intensidades calculadas para os ventos foram bem maiores do que as observadas na costa. Os resultados do modelo indicam que é possível associar o centro de alta pressāo do Atlântico Sul e as correspondentes elevaçōes de superfície paralelas à linha da costa a um sistema geostrófico de circulação oceânica. Por outro lado, a passagem de frentes frias na área induz sistemas transientes que modificam o padrão geostrófico, também mudando a configuração das isolinhas de elevação de superfície.

- Descriptors: Storm surges; Tides and currents; Pressure and winds; Hydrodynamical numerical modelling; Southeastern Brazilian shelf.

- Descritores: Ressacas; Marés e correntes; Pressão e vento; Modelagem numérica hidrodinâmica; Plataforma sudeste do Brasil.

\section{Introdução}

A área de estudo do presente trabalho corresponde à plataforma continental sudeste do Brasil, na região compreendida entre Ponta do Vigia (SC) e Cabo Frio
(RJ), desde a costa até aproximadamente a iśbbata de $\mathbf{1 0 0}$ m (Fig. 1).

Foi utilizado o modelo numérico hidrodinâmico desenvolvido para esta região por Harari $(1985,1987)$, o qual é baseado em Heaps (1972), visando representar processos de interesse nessa área. As forçantes desses processos hidrodinâmicos podem ser de origem astronômica ou meteorológica. 

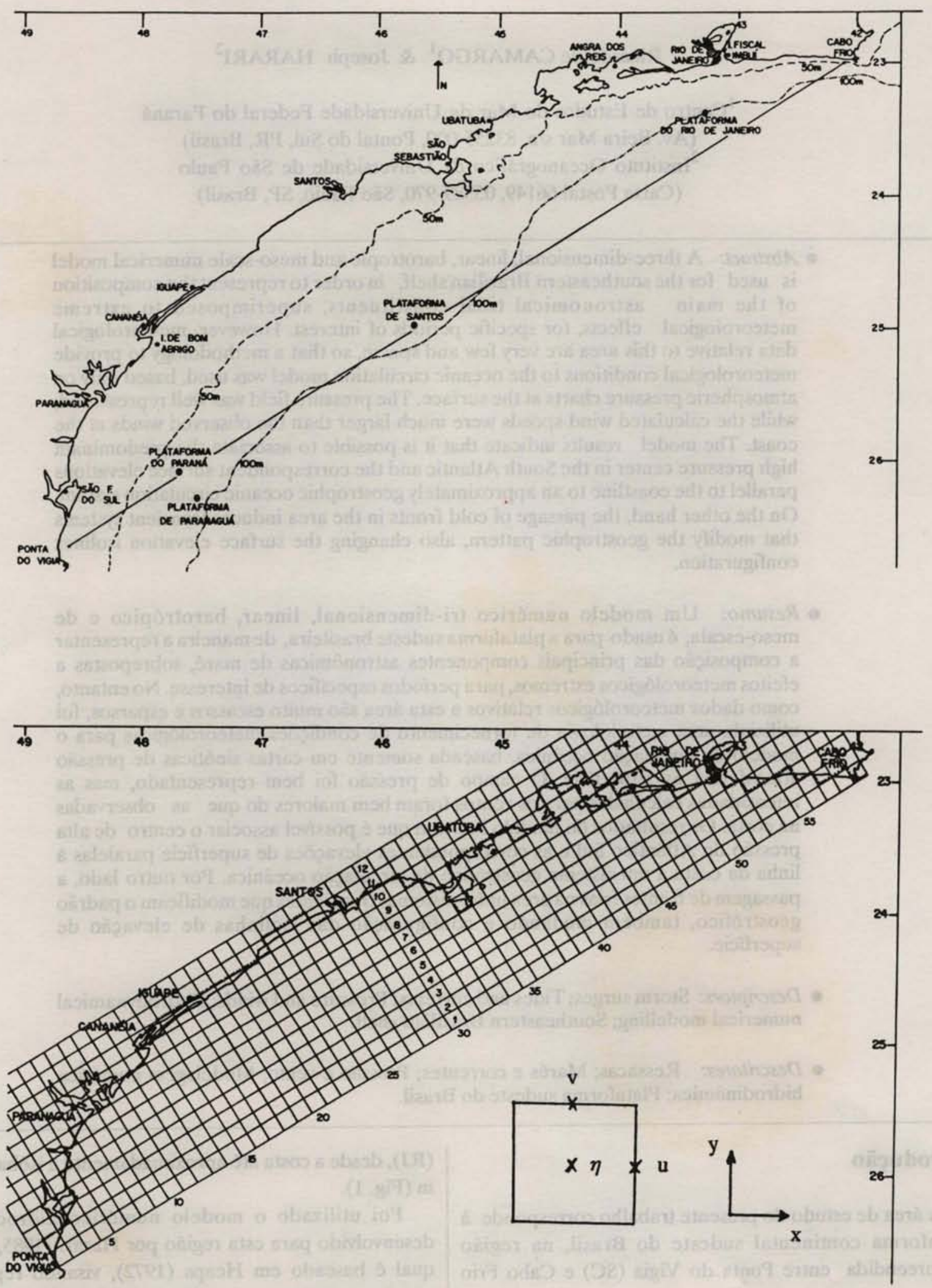

Fig. 1. Mapa geográfico da plataforma sudeste brasileira e grade oceanográfica utilizada no modelo. 
O objetivo deste trabalho é estudar a composiçāo das principais componentes astronômicas de maré da regiāo, sobreposta a efeitos meteorológicos extremos, em períodos específicos de interesse, através da aplicação de uma metodologia de especificação de condiçōes meteorológicas ao modelo de circulação marítima; esta metodologia é baseada apenas em mapas da pressão atmosférica na superfície, conforme Hasse \& Wagner (1971) e Hasse (1974). A partir de cartas sinóticas diárias, é feita uma reduçāo dos dados de pressāo atmosférica para a área de interesse, seguida de interpolaçōes para valores horários; com a estimativa dos gradientes de pressão e através da relação geostrófica, é possível calcular o vento geostrófico; finalmente, com o uso de correçōes empíricas, obtém-se o vento real aproximado, na superfície.

Varios trabalhos tem sido realizados na modelagem da resposta da plataforma sudeste brasileira a forçantes de origem meteorológica. Castro Filho (1985), após simular numericamente a circulação para condiçōes típicas de inverno nesta área, realizou um experimento com condiçōes de vento real transiente, similar a este trabalho. No entanto, os dados de vento utilizados por Castro Filho eram baseados em resultados de modelo numérico metcorológico de macro escala, com interpolaçōes no espaço e no tempo. Stech (1990) desenvolveu um estudo comparativo da dinâmica da referida plataforma com a South Atlantic Bight (Estados Unidos), simulando a atuação de campos de vento provenientes de modelos conceituais de frentes frias e de dados observados e extraídos de cartas sinóticas. Stech \& Lorenzzetti (1992) modelaram a resposta da plataforma sudeste brasileira à passagem de frentes frias, com base em modelos conceituais da evoluçāo desses sistemas meteorológicos, que por sua vez foram derivados da análise de dados costeiros de vento e de imagens de satélite. Já no presente estudo, é dada ênfase maior à composiçāo da circulação devida a efeitos meteorológicos com a circulaçāo de maré, visando reproduzir as elevaçōes do nível do mar ao longo das estaçōes costeiras, principalmente em períodos de elevaçōes excepcionais do nível do mar, como em Harari (1985); mas, neste trabalho, foi adicionalmente introduzido o uso da metodologia acima descrita para a imposiçāo de condiçōes de contorno meteorológicas no modelo da circulação marítima de Harari (op. cit.).

As componentes de maré consideradas nos processamentos do modelo ora apresentados sâo: $\mathrm{Q}_{1}, \mathrm{O}_{1}$, $\mathrm{P}_{1}, \mathrm{~K}_{1}, \mathrm{~N}_{2}, \mathrm{M}_{2}, \mathrm{~S}_{2}, \mathrm{~K}_{2}$ e $\mathrm{M}_{3}$. Os períodos escolhidos para as simulaçōes são: 27 de maio a 14 de junho de 1983 (19 dias) e 30 de Maio a 11 de junho de 1985 (13 dias). Tais períodos são caracterizados por grandes elevaçōes do nível médio do mar, por influência de sistemas meteorológicos intensos, como mostrado na Figura 2.

\section{Material e métodos}

O modelo utilizado nas simulaçōes que serão apresentadas foi desenvolvido por Harari $(1985,1987)$, baseado em Heaps (1972), sendo tridimensional, linear, barotrópico e de meso-escala. Ele resolve um sistema de equaçōes básicas formado pela equaçāo da continuidade e duas equaçōes do movimento na horizontal. Dessa forma se tem um sistema de três equaçōes a três incógnitas, que sāo a elevaçāo do nível do mar e as duas componentes horizontais de velocidade. Este sistema é resolvido pela aplicaçāo do Método de Galerkin para a dependência vertical das componentes de corrente, de modo a representar essas variáveis dependentes como uma expansāo em funçōes que possuem uma determinada estrutura vertical, chamadas funçōes base; os coeficientes das funçōes base consideram as dependências horizontal e temporal das componentes de corrente. Tal procedimento leva a um conjunto de equaçōes diferenciais para os coeficientes, o qual é resolvido com diferenças finitas no espaço horizontal e no tempo. Para o modelo em questão, foi utilizado o Método Espectral de Galerkin, com funçōes base ortogonais da forma cosseno. Detalhes sobre as equaçōes do modelo, condiçōes iniciais e de contorno, métodos de discretização, etc sāo descritos em Harari $(1984,1985)$.

Os processamentos do modelo requerem a especificaçāo das alturas de maré nos contornos abertos e a definição dos campos de gradiente de pressão e de friç̧ão do vento na superfície.

Para os pontos do contorno aberto, a parcela astronômica da elevação do nfvel do mar foi definida por previsōes harmônicas baseadas em análises de séries temporais de alturas de maré obtidas em três pontos da plataforma pertencentes a este contorno. As constantes harmônicas de amplitude ( $\mathrm{Hj})$ e de fase (Gj) das nove principais componentes astronômicas de maré nos três pontos amostrados foram obtidas através da aplicação dos métodos de análise de maré - harmônico e da resposta (Franco, 1988; Munk \& Cartwright, 1966). Nos demais pontos da fronteira aberta, os valores de $\mathrm{Hj} \mathrm{e} \mathrm{Gj}$ de cada uma das componentes foram obtidos através de interpolaçāo linear. Nas previsōes harmônicas citadas, foram consideradas correçōes nodais para os períodos de interesse. Como os períodos são relativamente curtos, assumiu-se que essas correçōes nāo variam nos períodos de previsão. Dessa maneira, foi possível especificar a altura da maré astronômica $\left(\eta_{\mathrm{A}}\right)$ em todos os pontos do contorno aberto, nos períodos de simulação. 
Já a inclusão da parcela de maré metcorológica nos pontos do contorno aberto $\left(\eta_{\mathrm{M}}\right)$ baseou-se em cstimativas das oscilaçōes horárias do nível médio do mar na costa, através da aplicaçāo de um filtro de médias móveis às alturas horárias de maré observadas nas estaçōes de Paranaguá, Cananéia, Santos, Ubatuba e Rio de Janeiro. Foi utilizado o filtro S24S24S25 sugerido por Godin (1972), o qual é particularmente útil na eliminaçāo de oscilaçōes diurnas, semi-diurnas etc, com a manutenção das variaçōes de longo período. Como essas estaçōes costeiras não pertencem ao contorno aberto, foi considerado um fator 0,75 para se obter o correspondente valor de $\eta_{M}$ nos pontos da fronteira aberta pertencentes às mesmas colunas da grade oceanográfica do modelo onde se encontram as estaçōes citadas. Alguns testes demonstraram ser este fator o mais indicado para este tipo de consideração, uma vez que as marés meteorológicas são amplificadas ao atingir águas costeiras progressivamente mais rasas. Similarmente às parcelas $\eta_{\mathrm{A}}$, foram realizadas interpolaçōes lineares para exprimir o campo de $\eta_{\mathrm{M}}$ ao longo de todo o contorno aberto.
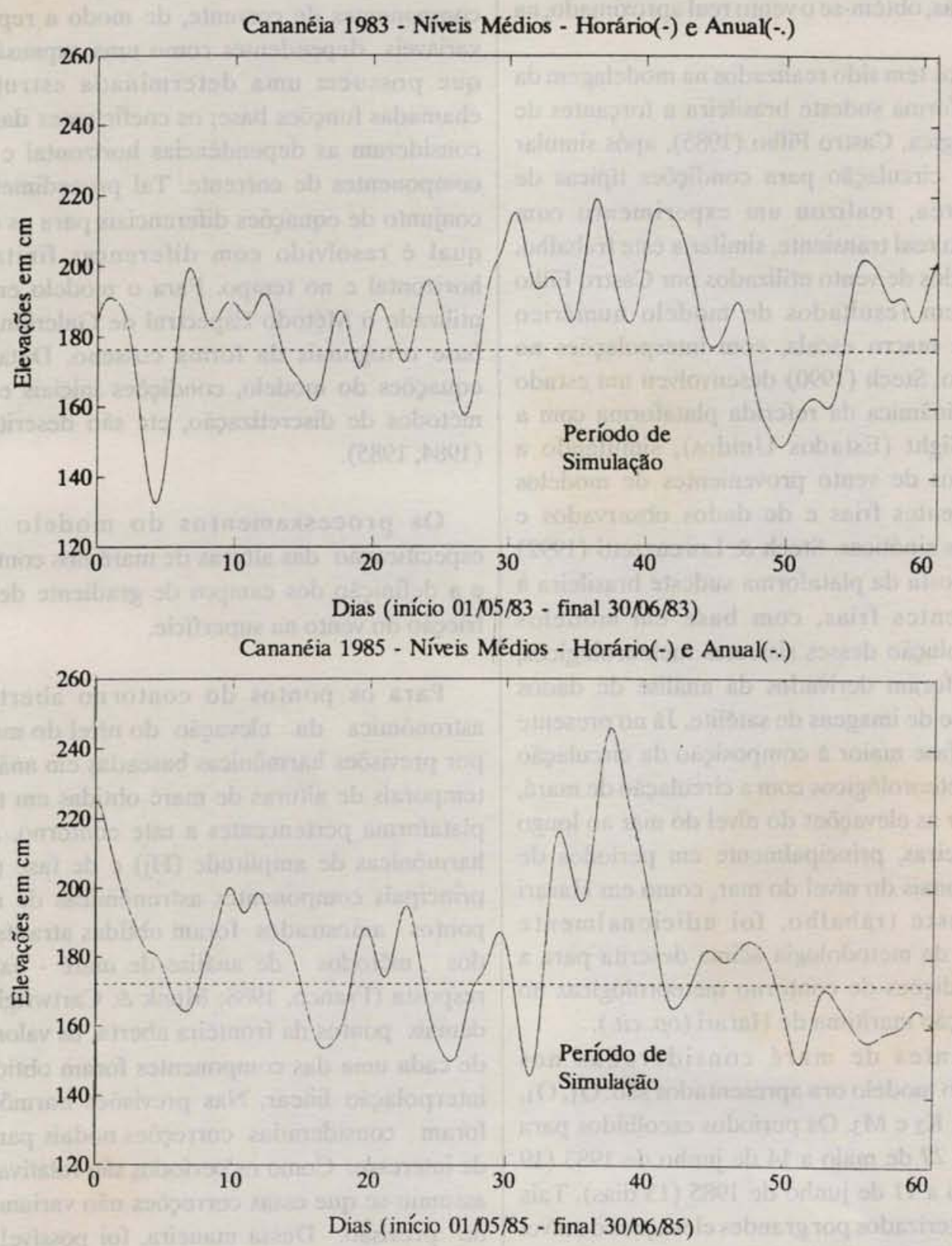

Fig. 2. Níveis médios horários e níveis médios anuais em Cananéia, para 1983 e 1985. 
Mais detalhes sobre as especificaçōes para as simulaçōes, tipo de grade oceanográfica e meteorológica, condiçōes de estabilidade, valores de coeficientes, etc são encontrados em Camargo (1991).

Para considerar as influências meteorológicas na regiāo em questāo, foram solicitados dados ao Instituto Nacional de Meteorologia (INMET), órgāo do Ministério da Agricultura.

Os dados fornecidos pelo INMET, referentes às estaçōes meteorológicas de Paranaguá, Iguape, Santos, Ubatuba e Rio de Janeiro, continham algumas lacunas, algumas de até dois dias, e nem todas as estaçōes possuiam dados de vento nos períodos de interesse. No campo da pressão atmosférica não houve dificuldade em realizar interpolaçōes para o preenchimento das lacunas, tendo em vista a pequena variabilidade desta variável no espaço e no tempo. Por outro lado, dados de vento interpolados contém um elevado grau de incerteza, devido à enorme variabilidade associada a esse campo. Com essas dificuldades, a utilização dos dados observados pelo INMET ficou um pouco comprometida.

A solução para este problema foi a de utilizar uma metodologia alternativa, com a obtenção de variáveis meteorológicas (pressāo atmosférica e vento, ambos na superfície do mar) a partir de cartas sinóticas. Com cartas sinóticas diárias de pressão atmosférica na superfície, são realizadas reduçōes dos dados na área de interesse, seguidas de interpolaçōes lineares no tempo, para ter esses valores em taxa horária. Através da relação geostrófica (balanço entre a força de Coriolis e a força de gradiente de pressão) é possível calcular o vento geostrófico; finalmente, com correçōes empíricas (Hasse \& Wagner, 1971; Hasse, 1974), se determina o vento real aproximado.

Este procedimento permite obter séries temporais de pressão e de vento já filtradas, ou seja, séries que contém apenas informaçōes sobre variaçōes de baixa freqüência, as quais são as principais responsáveis pela circulaçāo de meso escala induzida por efeitos meteorologicos.

A Figura 3 apresenta a grade meteorológica utilizada neste trabalho. A área modelada foi dividida em cinco partes, sendo que quatro delas possuem nay $=12$ linhas por $n a x=12$ colunas da grade oceanográfica e a restante nay $=12$ linhas por nax $=11$ colunas da mesma grade, totalizando assim a área completa (de 12 linhas por 59 colunas da grade oceanográfica). Em cada um desses cinco "elementos" da grade meteorológica, para cada hora de processamento, foram obtidos os dados meteorológicos de interesse: nos vértices se tem os valores de pressão atmosférica $\left(\mathrm{P}_{1}, \mathrm{P}_{2}, \mathrm{P}_{3}\right.$ e $\left.\mathbf{P}_{4}\right)$; e no centro se tem os valores da intensidade do vento $\mathrm{Va} e$ sua direção $\mathrm{D}_{\mathrm{a}}$, conforme a disposição indicada na Figura 3.

As cartas sinóticas utilizadas foram fornecidas pela Diretoria de Hidrografia e Navegação (DHN) do Ministério da Marinha.

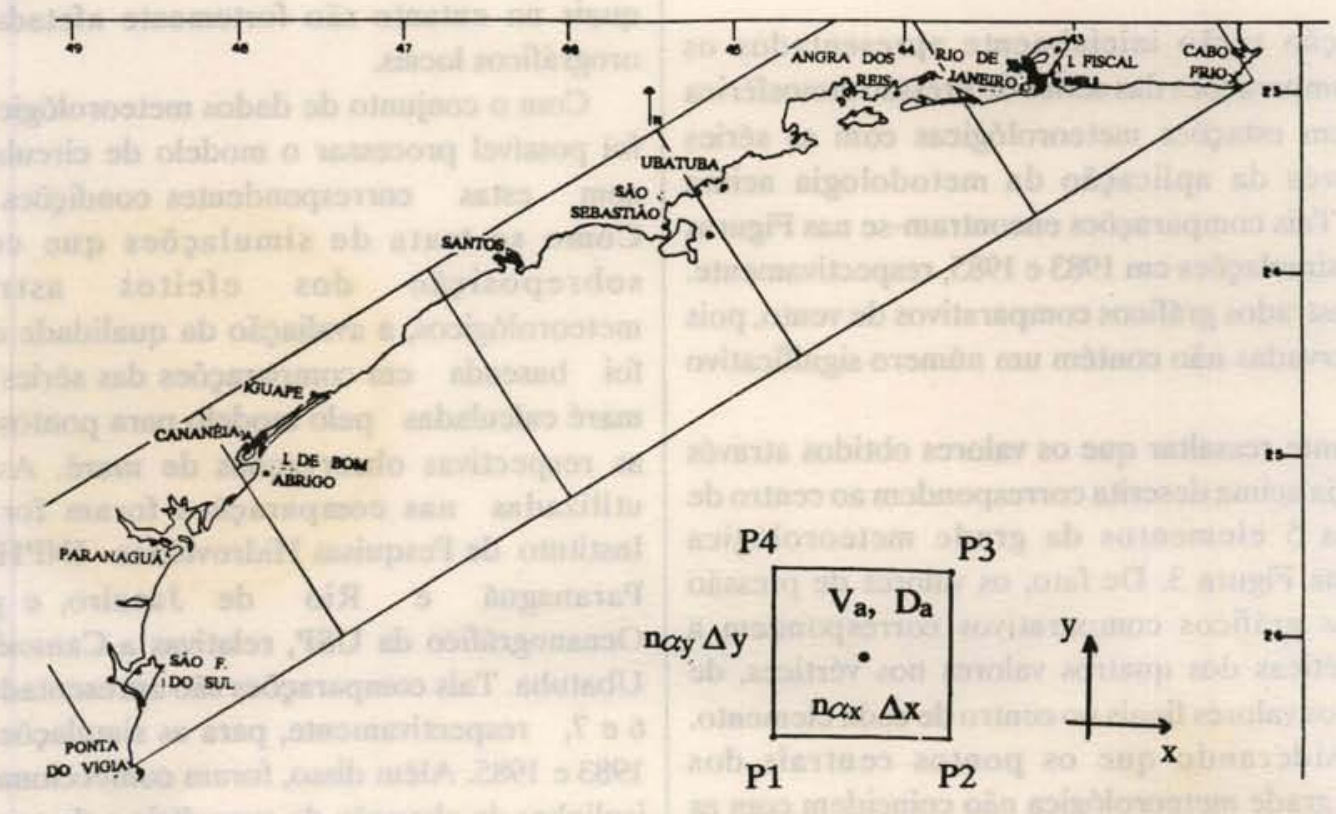

Fig. 3. A grade meteorológica do modelo. 
A correçāo empírica considerada para estimar o vento de superfície Va em função do vento geostrófico Vag é dada por:

$$
\mathrm{Va}=1.5+0.56 \mathrm{Vag}
$$

onde Va e Vag são em $\mathrm{m} / \mathrm{s}$; tendo a direção dos ventos origem no Norte geográfico e sentido positivo horário, a direçāo do vento de superfície $\mathrm{Da}$ corresponde a uma correção da direção do vento geostrófico Dag da forma:

$$
\mathrm{Da}=\mathrm{Dag}+18^{\circ}
$$

Na primeira expressão foi assumida uma condiçāo de coluna de ar estável; na segunda, o termo $+18^{\circ}$ representa o ângulo médio entre a direçāo do vento real e a direção do vento geostrófico. $\mathrm{O}$ efeito do atrito na superfície do mar diminui a velocidade do vento e portanto diminui a intensidade da força de Coriolis, o que gera a diferença típica de $18^{\circ}$ na direçāo. $O$ sinal positivo indica que, no caso em questão, correspondente ao hemisfério Sul, o vento real esta à direita do vento geostrófico, isto é, devido ao atrito, a deflexão do vento provocada pelo efeito de Coriolis se torna menor.

\section{Resultados}

Nesta seção serão inicialmente apresentados os gráficos de comparaçōes das séries de pressão atmosférica observadas em estaçōes meteorológicas com as séries obtidas através da aplicação da metodologia acima apresentada. Tais comparaçōes encontram-se nas Figuras 4 e 5, para as simulaçōes em 1983 e 1985 , respectivamente. Não serão mostrados gráficos comparativos de vento, pois as séries observadas não contém um número significativo de dados.

É importante ressaltar que os valores obtidos através da metodologia acima descrita correspondem ao centro de cada um dos 5 elementos da grade meteorológica apresentada na Figura 3. De fato, os valores de pressāo utilizados nos gráficos comparativos correspondem a médias aritméticas dos quatros valores nos vértices, de modo a obter os valores finais no centro de cada elemento. Mesmo considerando que os pontos centrais dos elementos da grade meteorológica não coincidem com as posiçōes das estaçōes costeiras, as comparaçōes realizadas tem um significado importante. Pode parecer inusitado utilizar os dados observados em estaçōes costeiras para as comparaçōes com os dados reduzidos de cartas sinóticas, uma vez que as próprias observaçōes foram usadas para a obtençāo dessas cartas. Porém, para a confecçāo de cartas sinóticas, principalmente sobre o oceano, onde as informaçōes são bastante exíguas, um grande nível de subjetividade $e ́$ introduzido. Portanto, com estes gráficos comparativos busca-se garantir a qualidade dos dados, das cartas e do próprio cálculo efetuado.

Os gráficos mostrados nas Figuras 4 e 5 sâo portanto relativos às comparaçōes de pressão atmosférica na superfície, sendo os valores expressos em milibares, referentes às 12h GMT dos dias das simulaçōes nos anos de 1983 e 1985. Pode-se observar uma boa concordância entre as séries, principalmente em Paranaguá, Iguape e Rio de Janeiro, enquanto que para Santos e Ubatuba existe uma diferença na referência (a qual pode ter sido causada por um eventual erro na redução ao nível do mar de dados observados em altitudes maiores); entretanto, também nesses casos, o padrão das curvas é similar.

A estatística comparativa das observaçōes de pressão nas estaçōes com as determinaçōes baseadas em cartas sinóticas é fornecida na Tabela 1, a qual apresenta valores de médias e desvios padrão. Na Tabela 2 encontram-se os valores de correlação linear e médias dos módulos das diferenças entre as séries. As correlaçōes são sempre superiores a 0,9, exceçāo feita a Rio de Janeiro em 1983. Pode-se observar que as médias das séries observadas e das séries obtidas são muito mais concordantes para 1983 do que para 1985. Já os valores dos desvios padrão sāo bastante concordantes para todos os pontos, nos dois períodos.

Quanto aos ventos calculados, os valores obtidos são aproximadamente o dobro das observaçōes costeiras, as quais no entanto sāo fortemente afetadas por efeitos orográficos locais.

Com o conjunto de dados meteorológicos calculados, foi possível processar o modelo de circulaçāo marítima com estas correspondentes condiçōes de contorno. Como se trata de simulaçōes que consideram a sobreposição dos efeitos astronômicos e meteorológicos, a avaliação da qualidade dos resultados foi baseada em comparaçōes das séries de alturas de maré calculadas pelo modelo para pontos da costa com as respectivas observações de maré. As observações utilizadas nas comparaçōes foram fornecidas pelo Instituto de Pesquisas Hidroviárias - INPH, referentes a Paranaguá e Rio de Janeiro, e pelo Instituto Oceanográfico da USP, relativas a Cananéia, Santos e Ubatuba. Tais comparaçōes são apresentadas nas Figuras 6 e 7, respectivamente, para as simulaçōes nos anos de 1983 e 1985. Além disso, foram confeccionados mapas de isolinhas de elevaçāo da superfície e de correntes médias nas colunas, para examinar as correspondentes condiçōes dominantes e transientes dos processos hidrodinâmicos (Figs 8 e 9). 

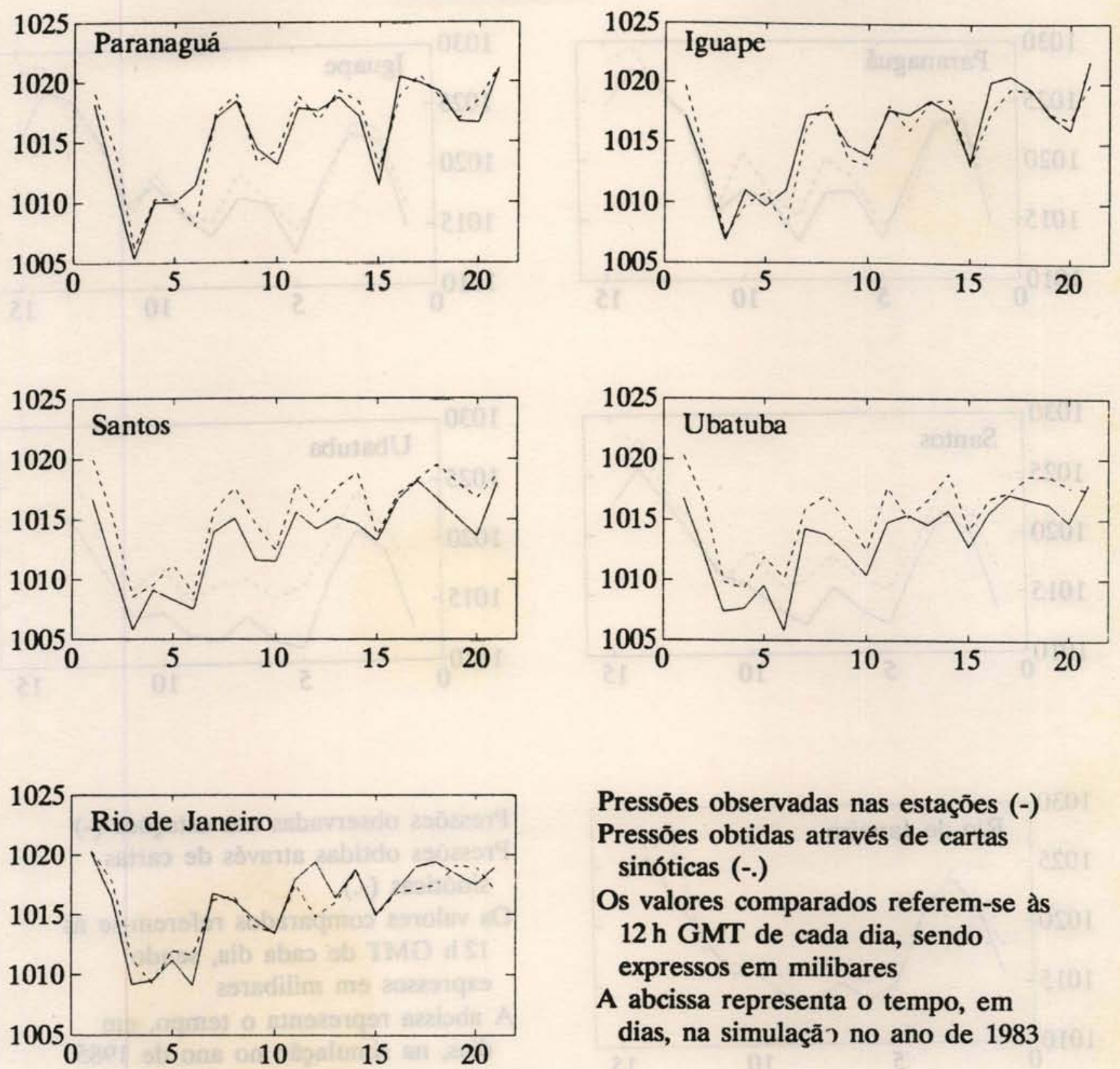

Pressões observadas nas estações (-) Pressōes obtidas através de cartas sinóticas (-.)

Os valores comparados referem-se às $12 \mathrm{~h}$ GMT de cada dia, sendo expressos em milibares

A abcissa representa o tempo, em dias, na simulaçã) no ano de 1983

Fig. 4. Comparação dos valores de pressão atmosférica na superfície observados e utilizados na simulaçắo de 1983. 

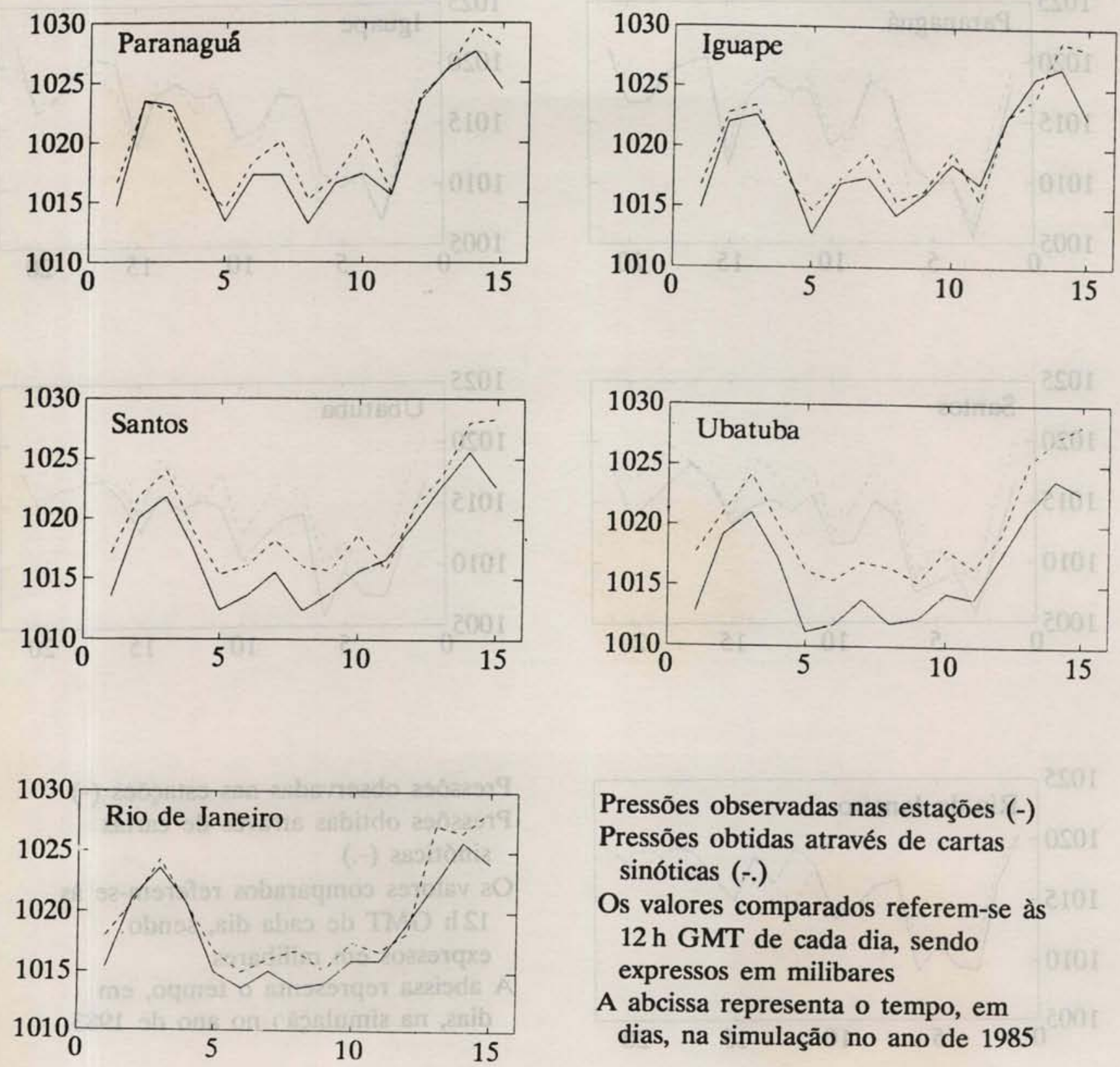

Pressões observadas nas estações (-)

Pressões obtidas através de cartas sinóticas (-.)

Os valores comparados referem-se às 12 h GMT de cada dia, sendo expressos em milibares

A abcissa representa o tempo, em dias, na simulação no ano de 1985

Fig. 5. Comparação dos valores de pressão atmosférica na superfície observados e utilizados na simulação de 1985. 
Tabela 1. Valores de médias e desvios padrão das médlas das sérles de pressäo atmosférica na superfície observadas e obtidas através de cartas sinóticas (em mb), nos períodos de interesse, nos anos de 1983 e 1985.

\begin{tabular}{|c|c|c|c|c|c|}
\hline & \multicolumn{3}{|c|}{1983} & \multicolumn{2}{|c|}{1985} \\
\hline & & Média & $\begin{array}{l}\text { Desvio } \\
\text { Padrão }\end{array}$ & Média & $\begin{array}{l}\text { Desvio } \\
\text { Padrão }\end{array}$ \\
\hline \multirow[t]{2}{*}{ Paranaguá } & Obs. & 1015.5 & 4.19 & 1019.5 & 4.76 \\
\hline & Calc. & 1015.9 & 4.24 & 1020.6 & 4.83 \\
\hline \multirow[t]{2}{*}{ Iguape } & Cbs. & 1015.9 & 3.91 & 1019.2 & 4.22 \\
\hline & Calc. & 1015.5 & 3.96 & 1020.2 & 4.59 \\
\hline \multirow[t]{2}{*}{ Sentos } & abs. & 1013.4 & 3.48 & 1017.6 & 4.26 \\
\hline & Calc. & 1015.5 & 3.56 & 1019.9 & 4.38 \\
\hline \multirow[t]{2}{*}{ Ubatuba } & Obs. & 1013.4 & 3.47 & 1016.3 & 4.32 \\
\hline & Calc. & 1015.6 & 3.15 & 1019.8 & 4.38 \\
\hline \multirow[t]{2}{*}{ Rio de Janeiro } & obs. & 1015.9 & 3.53 & 1018.4 & 4.23 \\
\hline & Calc. & 1015.8 & 2.91 & 1019.9 & 4.57 \\
\hline
\end{tabular}

Tabela 2. Valores de correlação linear e média do módulo da diferença entre séries de pressão atmosférica na superfície observadas e obtidas através de cartas sinóticas (em mb), nos períodos de interesse, nos anos de 1983 e 1985.

1983

Corr.Lin. M.M.Dif. Corr.Lin. M.M.Dif anuais, e o aspecto mais importante na escolha dos períodos é relativo às médias diárias do nível do mar, no caso em questão, em Cananéia.

O período considerado no ano de 1983 é caracterizado por elevaçōes de até $\mathbf{4 0} \mathrm{cm}$ acima do nível médio anual, com a manutenção desta grande elevação por cerca de sete dias, durante um período de maré de sizígia. Isto corresponde a cerca de $25 \%$ da variação da maré local. Já o período escolhido no ano de 1985 caracteriza-se por elevaçōes ainda maiores, de até $75 \mathrm{~cm}$ acima do nível médio deste ano, mas ocorrendo num período de no máximo 2 a 3 dias, com maré de quadratura. Esta elevaçāo, por sua vez, equivale a quase $50 \%$ da amplitude da maré em Cananéia. $O$ que se pretende neste estudo $e$ avaliar a qualidade dos resultados do modelo nas diferentes condiçōes consideradas: uma grande elevação numa época de sizígia e que perdurou por um longo período, em contraste com uma excepcional elevação num período de quadratura, que se extendeu por apenas dois a três dias (Fig. 2).

$\mathrm{Na}$ Figura 6, relativa ao processamento no ano de 1983, observa-se que os períodos de quadratura não são tão bem representados, principalmente em Paranaguá, Cananéia e Santos. Ao considerar todo o período de simulaçāo, as maiores discrepâncias em amplitude e fase ocorrem em Paranaguá, sendo ao redor de $40 \mathrm{~cm}$ e de duas horas, respectivamente, nas máximas elevaçōes. Esta discrepância diminui gradativamente para o Norte e não chega a $10 \mathrm{~cm}$ e a uma hora no Rio de Janeiro. De qualquer forma, os resultados obtidos sâo razoavelmente satisfatórios.

Um outro ponto a considerar nos resultados, quando confrontados com as cartas sinóticas, é que as condiçōes do vento nos dias 4 e 5 de junho de 1983 (entre 193 e 241 horas de processamento) eram principalmente do quadrante sul-sudoeste, o que causou um empilhamento de água na costa (devido ao transporte de Ekman); esse efeito, sobreposto às marés, não permitiu às vazantes abaixar suficientemente o nível do mar; assim, as enchentes consecutivas causaram as grandes elevaçöes do nfvel do mar observadas na costa. Os valores da direção do vento observado concordam razoavelmente bem com os valores calculados com a metodologia utilizada, embora as intensidades tenham sido superestimadas por esta metodologia em relação às correspondentes observaçōes.

A Figura 7 mostra as comparaçöes entre resultados do modelo e observaçōes, para a simulação do período no ano de 1985. Para tais comparaçōes, não havia observaçōes em Ubatuba, restringindo o conjunto de estaçōes a Paranaguá, Cananéia, Santos e Rio de Janeiro. Nesta figura, nota-se novamente que as quadraturas não são muito bem representadas. Em Paranaguá e Cananéia, a ocorrência de três preamares e três baixamares por dia, bem definidas, nāo foi reproduzida pelo modelo. Para Santos e Rio de Janeiro se tem resultados progressivamente melhores. 


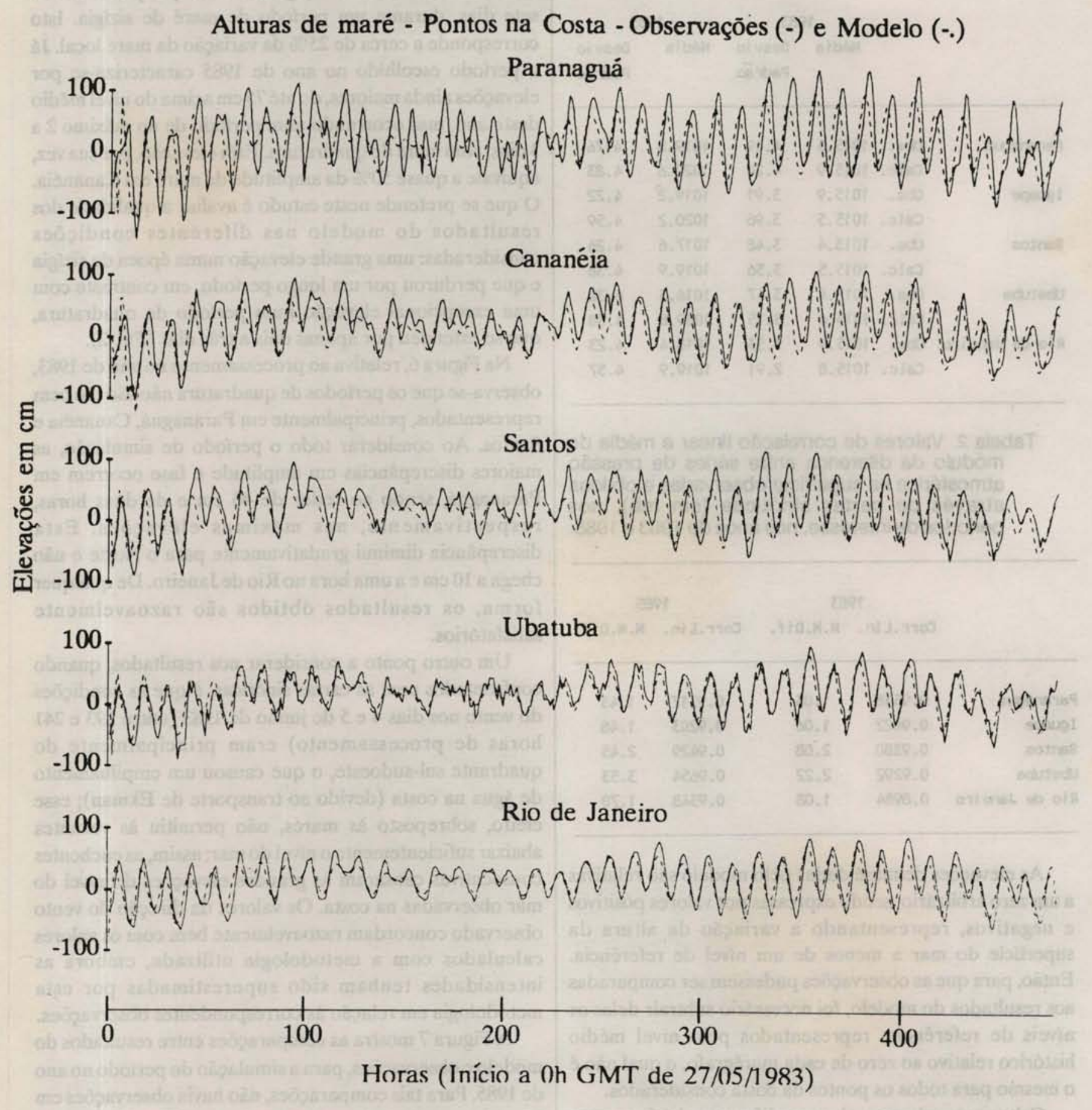

Fig. 6. Comparação das alturas de maré observadas e calculadas pelo modelo na simulação de 1983. 
Ainda quanto à Figura 7, é possível notar que os valores das preamares ocorridas entre 180 e 300 horas de processamento não foram bem simuladas pelo modelo, embora os instantes de ocorrência tanto de preamares quanto de baixamares, bem como os valores das baixamares, tenham sido bem reproduzidos. Mesmo assim, as simulaçōes não são totalmente satisfatórias, pois em Paranaguá a diferença de fase chegou a duas horas e no Rio de Janeiro a cerca de uma hora.
As cartas sinóticas relativas ao perfodo simulado no ano de 1985 indicam que, desde o dia 5 até o dia 9 de junho (entre 145 e 241 horas de processamento), os ventos foram predominantemente do quadrante Sul-Sudoeste na parte sul da área em estudo; como no caso da simulação anterior, o efeito desses ventos de quadrante Sul causou um acúmulo de água na costa que, adicionado à marés, ocasionou as grandes elevaçōes do nível do mar nos pontos da costa.
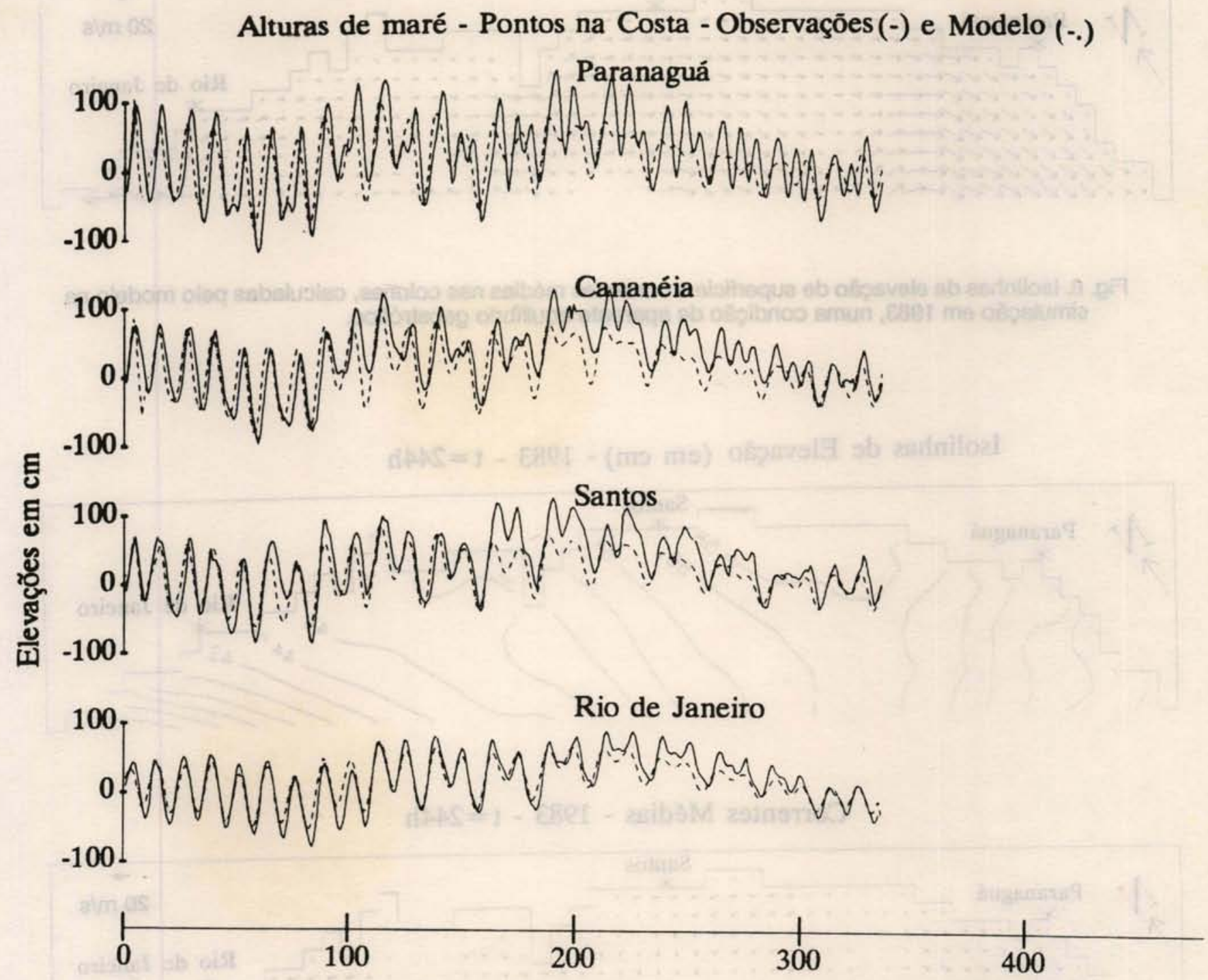

Horas (Início a 0h GMT de 27/05/1985)

Fig. 7. Comparação das alturas de maré observadas e calculadas pelo modelo na simulação de 1985. 
Isolinhas de Elevação $(\mathrm{em} \mathrm{cm})-1983-\mathrm{t}=145 \mathrm{~h}$

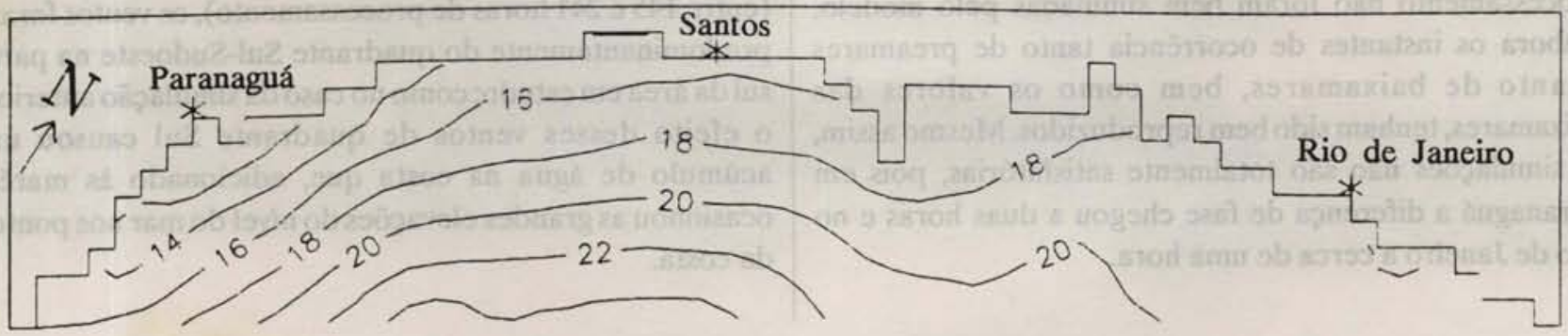

Correntes Médias $-1983-\mathrm{t}=145 \mathrm{~h}$

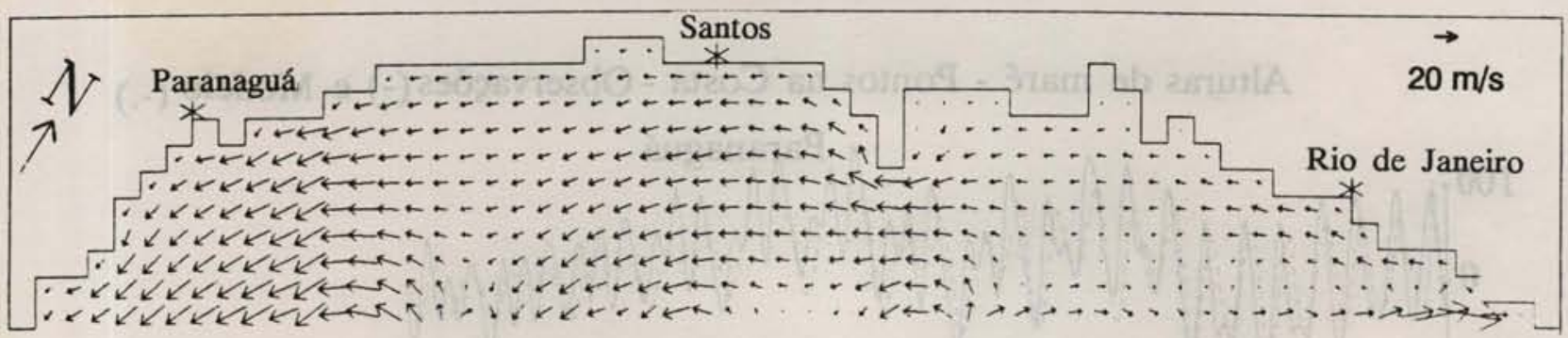

Fig. 8. Isolinhas da elevação de superfície e correntes médias nas colunas, calculadas pelo modelo na simulaçăo em 1983, numa condição de aparente equilibrio geostrófico.

Isolinhas de Elevação $(\mathrm{em} \mathrm{cm})-1983-\mathrm{t}=244 \mathrm{~h}$

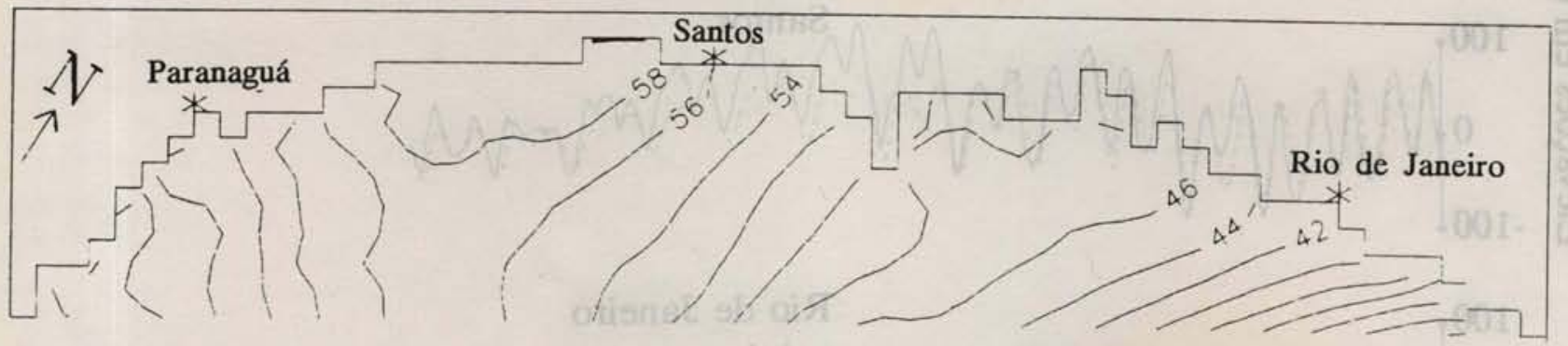

Correntes Médias - $1983-\mathrm{t}=244 \mathrm{~h}$

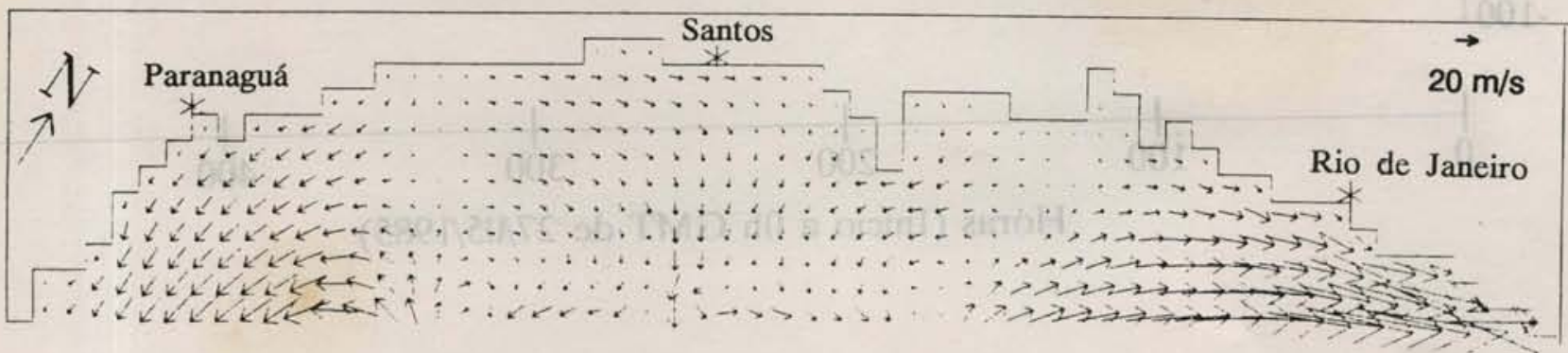

Fig. 9. Isolinhas da elevação de superfície e correntes médias nas colunas, calculadas pelo modelo na simulação em 1983, numa condição transiente induzida pela passagem de frentes frias. 
$\mathrm{Na}$ Tabela 3 encontram-se os valores das correlaçōes lineares e as médias dos módulos das diferenças entre as séries observadas e calculadas pelo modelo, para os períodos nos anos de 1983 e 1985. De uma maneira geral, os valores das correlaçōes sāo bastante satisfatórios, estando sempre acima de 0,7 , exceto para Paranaguá em ambos os períodos. Isto se deve ao fato da maré em Paranaguá apresentar características não-lineares, com diversas componentes de pequeno fundo não representadas pelo modelo. Já em relaçāo às médias dos módulos das diferenças entre as séries observadas e as resultantes do modelo, esta tabela demonstra que os menores valores são referentes a Rio de Janeiro e os maiores a Paranaguá.

Tabela 3. Valores de correlação linear e média do módulo da diferença entre séries de altura de maré observadas e modeladas $(e \mathrm{~m} \mathrm{~cm})$, para pontos da costa, na simulação da circulaçăo total (astronômica + meteorológica) nos períodos de interesse, nos anos de 1983 e 1985
1983

Corr.Lin. M.M.Dif.
1985

Corr.Lin. M.M.Dif

\begin{tabular}{llllll} 
Paranaguá & 0.5718 & 35.38 & 0.5975 & 35.15 \\
Canané ia & 0.7323 & 23.90 & 0.7294 & 28.23 \\
Santos & 0.7092 & 22.82 & 0.8162 & 24.40 \\
Ubatuba & 0.8183 & 14.54 & $\ldots \ldots .$. & $\ldots \ldots$. \\
\hline Rio de Janeiro & 0.8417 & 13.29 & 0.8964 & 13.25
\end{tabular}

Outra comparação estatística é apresentada na Tabela 4, para 1983 e 1985, mostrando os desvios padrão das médias, tanto das observaçōes como dos resultados do modelo. Estes valores indicam uma atenuação das oscilaçōes por parte do modelo, principalmente em Paranaguá, provavelmente devido à baixa resolução do modelo em áreas costeiras rasas.

Tabela 4. Valores dos desvios padrão das médias das séries de alturas de maré observadas e calculadas pelo modelo $(\mathrm{em} \mathrm{cm})$, para pontos da costa, na simulação da circulação total (astronômica + meteorológica) nos períodos de interesse, nos anos de 1983 e 1985

1983

1985

Observaç̃oes Modelo Observações Modelo

\begin{tabular}{l|l|l|l|l|} 
Paranaguá & 49.89 & 32.99 & 52.17 & 35.45 \\
Canané ia & 38.73 & 37.46 & 44.32 & 36.39 \\
\hline Santos & 38.25 & 30.03 & 43.09 & 31.46 \\
\hline Ubatuba & 32.12 & 26.32 & $\ldots . .$. & $\ldots . .$. \\
\hline Rio de Jane iro & 32.52 & 23.71 & 37.76 & 27.35 \\
\hline
\end{tabular}

\section{Discussão}

Deve-se observar que componentes de maré de pequeno fundo não foram consideradas no modelo. Entretanto, a sua existência é um indicativo de influências não lineares importantes, que modificam inclusive as componentes principais de maré. Conseqüentemente, o fato de efeitos não lineares influenciarem as marés observadas e de não estarem sendo considerados nas marés modeladas em sua propagaçäo do contorno aberto para a costa, provoca as discrepâncias nas comparaçōes acima citadas. Provavelmente por causa disso as quadraturas não são tão bem reproduzidas pelo modelo, tendo sido notadas significativas diferenças nas máximas elevaçōes, principalmente na simulação no ano de 1985.

Quanto à metodologia de obtençāo de dados meteorológicos desenvolvida por Hasse \& Wagner (1971) e Hasse (1974), e que foi aqui utilizada, as seguintes consideraçōes podem ser feitas.

As pressōes obtidas através da reduçāo dos dados das cartas sinóticas, quando comparadas às observaçōes nas estaçōes, conduzem a bons resultados, conforme pode ser visto nas Figuras 4 e 5, referentes às simulaçōes nos anos de 1983 e 1985, respectivamente.

A partir dos valores diários de pressão na grade meteorológica, foi realizada uma interpolação em base horária; a seguir, também a tentativa de se obter o vento real aproximado, a partir desses valores interpolados e da relação geostrófica com correçōes, conduziu a valores razoáveis. Contudo, comparaçōes desses cálculos com observaçōes de vento são prejudicadas pela baixa qualidade das mediçōes. Por outro lado, a metodologia utilizada apresenta as vantagens de se ter um caráter filtrado nos campos de pressão e vento e, principalmente, se ter um esquema utilizável em processos de simulação e previsão operacionais.

A estatística basica comparativa demonstra, com efeito, uma concordância significativa entre as pressōes calculadas pelas cartas sin6́ticas e as observadas, com altos valores do coeficiente de correlação (Tab. 1 e 2).

Com este procedimento, obtém-se séries de dados de pressāo e vento que, quando incorporados ao modelo como condiçâo de contorno na superfície, permitem a modelagem da correspondente circulação marítima.

Também a adoção de informaçōes da maré meteorológica no contorno, baseadas em proporcionalidade com valores costeiros, conduziu a simulaçōes satisfatórias. Entretanto, este esquema não seria utilizável em previsōes operacionais na área. Por outro lado, a especificação desses valores poderia ser realizada a partir dos cálculos de um modelo de macro-escala do Atlântico Sul. 
As séries de alturas de maré calculadas pelo modelo c observadas nāo sāo totalmente coincidentes na parte sul da regiāo em estudo, devido à geometria e à inclinação do fundo desta porção da plataforma, o que faz com que a interação das componentes da maré astronômica pura e da circulação devida a efeitos meteorológicos seja fortemente não linear e, portanto, não plenamente representável neste modelo linear.

De qualquer forma, as simulaçōes apresentadas neste trabalho constituem uma primeira aproximação dos efeitos meteorológicos extremos observados nos dois períodos simulados. Sob esse aspecto, e levando em consideração a metodologia operacional de introdução de dados meteorológicos, os resultados finais das simulaçōes sāo bastante satisfatórios.

Castro Filho (1985) utilizou dados de vento na superfície fornecidos pelo National Meteorological Center (NMC) dos Estados Unidos da América, produzidos por modelo atmosférico de macro escala, que foram devidamente interpolados no espaço e no tempo e multiplicados por um fator 2 , com base em comparaçōes com observaçōes de navios. Esta simulação foi referente ao período de 29/08 a 08/09/1979 e apresenta conclusōes de grande interesse, principalmente através do aninhamento em grades menores, com ênfase ao Canal de São Sebastiāo. Enquanto que na grade maior as características do fluxo são predominantemente geostróficas, em grades de maior resolução, efeitos ageostróficos são predominantes.

Stech (1990) e Stech \& Lorenzzetti (1992) pesquisaram a resposta da plataforma sudeste brasileira a frentes frias médias, concluindo que: nos espectros de vento, o principal pico tem periodicidade entre 5 e 6 dias, sendo associado a frentes frias que se deslocam longitudinalmente na direção paralela à costa; com isso, a parte sul do domínio é afetada mais intensamente por estes sistemas meteorológicos; o tempo necessário para que o oceano atinja um estado de equilibrio é da ordem de 1,5 a 2,5 dias; o balanço de momento normal à costa é geostrófico, o que nāo ocorre paralelamente à costa; e, finalmente, as anomalias do nível do mar se propagam ao longo da costa, em fase com os sistemas forçantes.

O presente trabalho apresenta algumas similaridades com os de Castro Filho (1985), Stech (1990) e Stech \& Lorenzzetti (1992), como por exemplo: pesquisas para a implementação de dados meteorológicos em modelos oceânicos; uma razoável reprodução da maré meteorológica em estaçōes costeiras, apenas prejudicada por efeitos de pequena escala e a imposiçāo de condiçōes de contorno nảo absolutamente exatas; a obtenção de circulações com características geostróficas para ventos típicos; efeitos mais intensos na parte sul da área modelada; e, finalmente, propagação das anomalias do nível do mar ao longo da costa, em fase com os sistemas forçantes.

\section{Conclusōes}

O objetivo principal deste trabalho foi o de aplicar uma metodologia de obtenção de dados meteorológicos desenvolvida por Hasse \& Wagner (1971) e Hasse (1974), visando considerar as influências dos campos de pressão atmosférica e vento na circulação oceânica de meso-escala nesta plataforma. Para tanto, foi utilizado o modelo numérico hidrodinâmico linear desenvolvido por Harari $(1984,1985)$ para esta regiāo.

De fato, a metodologia desenvolvida para a obtenção dos dados de pressão atmosférica e vento descreve razoavelmente bem os fenômenos meteorológicos observados nos períodos de interesse. E importante ressaltar que foram utilizadas cartas sinóticas diárias, as quais não contêm informaçōes sobre oscilaçōes de menor período e, portanto, não se tem a variação diurna da pressão e do vento. No entanto, as variaçōes de maior interesse para o presente estudo são as de baixa frequeência, com períodos da ordem de alguns dias, e que são as maiores responsáveis pela circulação gerada por efeitos meteorológicos. Desta forma, o caráter filtrado das séries de variáveis meteorológicas obtidas é muito adequado para os processamentos considerados.

Deve-se enfatizar que os dados de pressāo observados nas estaçōes do INMET seriam utilizáveis, mas optou-se pelos dados reduzidos de cartas sińticas, de modo a manter a uniformidade de parâmetros atmosféricos. De qualquer forma, a comparação dos dados de pressāo obtidos a partir das cartas com os das estaçōes demonstra sua boa concordância (Fig. $4 \mathrm{e} 5 \mathrm{e}$ Tab. $1 \mathrm{e} 2$ ). Já a utilização direta dos dados de vento observados em estaçōes costeiras causaria uma série de dificuldades, fornecendo forçantes errôneas e pouco efetivas para a circulação oceânica ao largo. Conseqüentemente, foi utilizada a formulaçāo de Hasse \& Wagner (1971) e Hasse (1974), com a estimativa do vento de superfície a partir de cartas sinóticas de pressāo, através do cálculo do vento geostrófico e sua correção por expressōes empíricas.

As intensidades dos ventos obtidas foram muito maiores do que as dos observados na costa. Entretanto, estes últimos sofrem muita influência da topografia local $\mathrm{e}$ contém alto grau de incerteza.

Quanto às elevações do nível do mar nos contornos, a parcela meteorológica foi adotada como sendo proporcional às correspondentes observaçōes costeiras.

A respeito dos resultados obtidos nas simulaçōes hidrodinâmicas, pode-se dizer que quando há um padrão definido de vento, como por exemplo, o associado à condição dominante da Alta do Atlântico Sul, são observadas isolinhas de elevação de superfície que 
acompanham a linha da costa, isto $c$, a linha da costa $\mathrm{c}$ as isolinhas de elevação ficam aproximadamente paralelas (Fig. 8).

Por outro lado, quando ocorre uma condição transiente extrema, com a passagem de frentes frias sucessivas (como na simulação do ano de 1983), tem-se grandes mudanças na direção do vento e o modelo sugere que as isolinhas de elevação de superfície se tornam aproximadamente transversais à linha da costa (Fig. 9).

Já na simulaçāo do ano de 1985, não houve esta feição acentuada de isolinhas de elevação transversais à linha da costa como na simulação do ano de 1983; mas, de qualquer forma, nos períodos de vento transiente observou-se uma modificação no padrão paralelo destas isolinhas com a linha da costa.

Em princípio, pode-se associar a predominância da Alta do Atlântico Sul e as isolinhas de elevação paralelas à costa com um sistema aproximadamente geostrófico da circulaçāo oceânica. Por outro lado, a passagem de frentes na área induz sistemas transientes que modificam o padrão geostrófico citado, mudando também a configuração das isolinhas de elevação.

As correlaçōes entre séries observadas e fornecidas pelo modelo, mostradas na Tabela 3 , indicam resultados satisfatórios. Em princípio, um aprimoramento do método de obtenção dos parâmetros meteorológicos, como por exemplo, através de cartas sinóticas obtidas em intervalos de 6 horas, tornará possível melhorar bastante a qualidade das simulaçōes.

Para esquemas operacionais de previsão da circulação marítima na plataforma estudada com a metodologia aqui utilizada, espera-se que modelos oceânicos de macro-escala possam fornecer a maré meteorológica no contorno desta área e que modelos atmosféricos possam produzir previsōes de grande precisão para o campo de pressão na superfície.

Atualmente, já são realizadas previsōes em escala global pelo National Meteorological Center (NMC) dos EUA, com resolução para o Hemisfério Sul de $2,5^{\circ} \mathrm{em}$ latitude e longitude, a cada 12 horas, para períodos de três dias. Existem também modelos de meso-escala como o Regional Atmospheric Modeling System, que podem ter alta resolução, para estudos de fenômenos atmosféricos locais. O Centro de Previsāo do Tempo e Estudos Climáticos (CPTEC), do Instituto Nacional de Pesquisas Espaciais (INPE), no Brasil, deverá em futuro próximo realizar previsōes numéricas das condiçōes meteorológicas na área marítima do presente estudo. Além disso, um modelo de escala oceânica, como o apresentado em Harari (1991), poderá fornecer as alturas de maré meteorológica no contorno aberto. Assim, espera-se no futuro poder aprimorar o trabalho aqui apresentado, de modo a obter resultados cada vez melhores.

\section{Agradecimentos}

Agradecemos ao Dr Pedro Leite da Silva Dias, do Instituto Astronômico e Geofísico da USP, e ao Dr Joāo Antônio Lorenzzetti, do Instituto Nacional de Pesquisas Espaciais, pela colaboração prestada para a elaboração deste trabalho, e à Fundação de Amparo à Pesquisa do Estado de Sâo Paulo e ao Conselho Nacional de Desenvolvimento Científico e Tecnológico, pela concessão de Bolsa de Mestrado ao primeiro autor. Agradecemos também ao Instituto Oceanográfico da USP e ao Centro de Computação Eletrônica da USP, pelo apoio aos trabalhos realizados.

\section{Referências bibliográficas}

CAMARGO, R. 1991. Modelagem das ondas de maré astronômica e meteorológica na plataforma sudeste brasileira. Dissertação de mestrado. Universidade de São Paulo, Instituto Oceanográfico. 90p.

CASTRO FILHO, B. M. de 1985. Subtidal response to wind forcing in the South Brazil Bight during winter. Ph.D. Dissertation. University of Miami, RSMAS. 211p.

FRANCO, A. S. 1988. Tides: fundamentals, analysis and prediction. 2a. Ed., São Paulo, Fundação Centro Tecnológico de Hidráulica. 249p.

GODIN, G. 1972. The analysis of tides. Liverpool, Liverpool University Press. 264p.

HARARI, J. 1984. Modelo numérico hidrodinâmico tri-dimensional linear da plataforma continental sudeste do Brasil. Tese de doutorado. Universidade de São Paulo, Instituto Astronômico e Geofísico. 203 p.

1985. Desenvolvimento de um modelo numérico hidrodinâmico tri-dimensional linear, para a simulaçāo e a previsão da circulaçāo na plataforma brasileira entre $23^{\circ}$ e $26^{\circ} \mathrm{S}$. Bolm Inst. oceanngr., S Paulo, 33(2):159-191.

1987. Programa de computador de modelo numérico hidrodinâmico tri-dimensional linear em meso-escala. Relat. int. Inst. oceanogr. Univ. S Paulo, (15):1-25.

1991. Modelo numérico hidrodinâmico tridimensional linear do Oceano Atlântico Sul. Tese de livre-docência. Universidade de São Paulo, Instituto Oceanográfico. 2v. 
HASSE, L. 1974. On the surface to geostrophic wind relationship at sea and the stability dependence of the resistance law. Beitr. Phys. Atmos., 47:45-55.

\& WAGNER, V. 1971. On the relationship between geostrophic and surface wind at sea. Mon. Weath. Rev., 99:255- 260.

HEAPS, N. S. 1972. On the numerical solution of the three dimensional hydrodynamical equations, for tides and storm surges. Mém Soc. r. Sci Liège, ser 6, 2:143-180.

MUNK, W. H. \& CARTWRIGHT, D. E. 1966. Tidal spectroscopy and prediction. Phil. Trans. R. Soc., 259(1105):533-581.
STECH, J. L. 1990. Um estudo comparativo da dinâmica da circulaçāo de inverno entre as plataformas continentais das costas sudeste do Brasil e dos Estados Unidos utilizando um modelo numérico. Tese de doutoramento. Universidade de São Paulo, Instituto Oceanográfico. 224 p.

\& LORENZZETTI, J. A. 1992. The response of the South Brazil Bight to the passage of wintertime coldfronts. J. Geoph. Res., 97(C6): 9507-9520.

(Manuscrito recebido 4 março 1993; revisto 5 maio 1994; aceito 30 junho 1994) 